\title{
BMJ Open Metabolic syndrome in native populations living at high altitude: a cross-sectional survey in Derong, China
}

\author{
Xiaofei Huang, ${ }^{1}$ Yongbo Hu, ${ }^{2,3}$ Longqi Du, ${ }^{4}$ Xiaolong Lin, ${ }^{5}$ Wenli Wu, ${ }^{6}$ Lijun Fan, ${ }^{7}$ \\ Libo Li, ${ }^{8}$ Xiaowei Zhong, ${ }^{1}$ Qiyong Gong, ${ }^{2}$ Li Gao, ${ }^{3}$ Weihong Kuang (1) ${ }^{9}$
}

To cite: Huang X, Hu Y, Du L, et al. Metabolic syndrome in native populations living at high altitude: a cross-sectional survey in Derong, China. BMJ Open 2020;10:e032840. doi:10.1136/ bmjopen-2019-032840

- Prepublication history for this paper is available online. To view these files, please visit the journal online (http://dx.doi. org/10.1136/bmjopen-2019032840).

$\mathrm{XH}$ and $\mathrm{YH}$ are joint first authors.

Received 15 July 2019

Revised 28 November 2019

Accepted 10 December 2019

Check for updates

(C) Author(s) (or their employer(s)) 2020. Re-use permitted under CC BY-NC. No commercial re-use. See rights and permissions. Published by BMJ.

For numbered affiliations see end of article.

Correspondence to

Dr Li Gao; gaoli1956@163.com

Dr Weihong Kuang; kwh20194@126.com

\section{ABSTRACT}

Objective The metabolic syndrome is a major risk factor for cardiovascular disease. Little information exists on the prevalence of the metabolic syndrome at high-altitude areas in China. We aimed to estimate the prevalence of metabolic syndrome and its individual components at high altitude.

Methods A cross-sectional survey of 5053 adults living in Derong from elevation of 2060 to $3820 \mathrm{~m}$ was carried out in 2013. Metabolic syndrome was defined according to the Chinese Diabetes Society criteria.

Results The overall prevalence of metabolic syndrome was $3.6 \%$ (5.9\% in men and $1.8 \%$ in women) in Derong, China. Obesity and hypertension were more prevalent among adults than dyslipidaemia and hyperglycaemia at high altitude. The prevalence of metabolic syndrome was higher in township than countryside residents $(6.6 \%$, $11.9 \%$ in men and $1.5 \%$ in women vs $3.0 \%, 4.6 \%$ in men and $1.8 \%$ in women). Men with age $30-59$ years old had a much higher prevalence of metabolic syndrome than women. Men, township, middle and old age residents had a higher risk of metabolic syndrome. The risk of obesity and dyslipidaemia decreased and the risk of hypertension increased in very high altitude $(\geq 3000 \mathrm{~m})$ residents.

Conclusion In Derong, despite the relatively low prevalence of metabolic syndrome, hypertension and obesity are more prevalent in adult residents. And metabolic syndrome is more concentrated in township and male residents. These people also have a higher risk of metabolic syndrome. Therefore, it is necessary to develop a national strategy for the prevention and treatment of metabolic syndrome for high-risk population at high altitude in China.

\section{INTRODUCTION}

As a result of great economic growth and social changes within last 30 years, ischaemic heart disease and stroke have become the leading causes of mortality in China. ${ }^{1}$ One of the most important risk factors of these diseases is metabolic syndrome, which is characterised by obesity, hyperglycaemia, hypertension and dyslipidaemia. ${ }^{2}$ Changes in lifestyle and diet have led to an increase in prevalence of metabolic syndrome. Recent study reported that the prevalence of metabolic syndrome

\section{Strengths and limitations of this study}

This study is a large-scale survey of metabolic syndrome in high-altitude areas which existing data are insufficient.

- This study discusses the distribution of different components of metabolic syndrome in high-altitude areas.

- Further longitudinal study is necessary to find out the causality between metabolic risk factors and metabolic syndrome at high altitude.

ranged between $27.4 \%$ and $39 \%$ in Chinese population, ${ }^{3-5}$ similar to that in the USA. ${ }^{6}$

It is estimated that over 400 million people worldwide reside in high-altitude areas above $1500 \mathrm{~m}$. In China, plateau and mountain areas account for more than a half of the national territory, and more than 70 million people live in these areas of altitude over $1800 \mathrm{~m}$.

High-altitude environment affects the incidence of metabolic syndrome from multiple aspects. First of all, people living in high-altitude areas tend to be leaner when compared with those living in low-altitude areas, and this inverse association is independent of lifestyle, ethnicity and income. ${ }^{7}$ Second, as obesity is a well-established risk factor for type 2 diabetes, the less prevalent in obesity can explain the lower prevalence of diabetes at higher altitudes. ${ }^{8}$ Third, there is a positive correlation between altitude and the prevalence of hypertension. ${ }^{9}$ Fourth, several epidemiological investigations suggest that high altitudes could be associated with dyslipidaemia. ${ }^{10}$ Due to the above comprehensive impact on the components of metabolic syndrome, it is difficult to estimate the prevalence of metabolic syndrome at high altitude in theory.

Derong County is a small county of Sichuan province, which locates on the southeast edge of the Tibetan plateau. It has a population of 26000 by 2014, mainly Tibetan. It had a 
gross regional product of 81 million dollars (506 million Chinese Yuan) in 2013. The whole county locates above the altitude of $2000 \mathrm{~m}$, with the highest elevation of $5599 \mathrm{~m}$. The county belongs to the subtropical arid valley climate zone. The average temperature in January is $5.5^{\circ} \mathrm{C}$, the average temperature in July is $21.6^{\circ} \mathrm{C}$ and the average annual precipitation is $327.1 \mathrm{~mm}$. Because of the relatively large elevation difference, the climate changes vertically.

Since the imbalance of economic development and the inconvenience of transportation, most studies of metabolic syndrome in China are carried out in the central and eastern plains regions. ${ }^{1112}$ Research data of the prevalence of metabolic syndrome in high-altitude areas of western China remain insufficient.

We therefore did a large-scale cross-sectional survey in Derong to: (1) explore the prevalence of metabolic syndrome and its components of Derong; (2) analyse the distribution of different components of metabolic syndrome; and (3) examine the distributions of these problems by gender, age and residence regions.

\section{MATERIALS AND METHODS \\ Study population}

The Health Examination Program of Derong County was a free health examination programme for all native resident of Derong. In this program, a total of 10626 people were recruited from November 2013 to December 2013. And 8138 people completed all the survey and examinations. The metabolic syndrome analysis was restricted to individuals whose age was 18 and above $(\mathrm{n}=5053)$. Among them, 92.3\% were Tibetans $(\mathrm{n}=4663), 18.6 \%$ had current smoking habits $(\mathrm{n}=938)$ and $14.9 \%$ had frequent alcohol consumption $(\mathrm{n}=754)$. People lived from 2060 to $3820 \mathrm{~m}$, and $28.4 \%(\mathrm{n}=1433), 44.0 \%(\mathrm{n}=2225)$ and $27.6 \%$ $(\mathrm{n}=1395)$ lived in $2000-2499 \mathrm{~m}, 2500-2999 \mathrm{~m}$ and over $3000 \mathrm{~m}$, respectively. Oral informed consent was obtained from every participant before data collection.

\section{Study design}

Data were collected from eight examination centres throughout the county. During the initial assessment, trained doctors administered a standard questionnaire in Chinese. They obtained information on demographic characteristics, including age, gender, nationality and residential regions (township or countryside). The township was defined as a settlement where the government of its district was located and had necessary public services such as hospitals, schools and postal services. The rest residence region was defined as countryside correspondingly. According to this definition, 12 and 143 settlements were considered as township and countryside, respectively. The altitudes of settlements were determined by Google Maps. People lived in township and countryside had average altitudes of 2431 and $2806 \mathrm{~m}$, respectively. The questionnaire included questions related to the diagnosis and treatment of hypertension and diabetes.
Women were asked whether diabetes had been diagnosed during pregnancy and whether it had been diagnosed when they were not pregnant.

Then, anthropometric measurements and blood pressure were obtained by trained and certified nurses by use of standard protocols and techniques. ${ }^{13}$ Bodyweight and height were measured twice during the examination. Three blood pressure measurements were obtained with the subjects in the seated position after 5 min of rest. Body mass index (BMI) was calculated as weight $(\mathrm{kg})$ divided by the square of height $(\mathrm{m})$.

Overnight fasting blood samples were collected for the measurement of plasma glucose and lipid panel the next day. Concentrations of glucose and lipid panel were assessed enzymatically by automatic biochemical analyser (Mindray, Shenzhen, China) in the clinical laboratory of Derong county people's hospital.

The metabolic syndrome was defined according to the Chinese Diabetes Society (CDS) criteria as the presence of three or more of the following four components: (1) BMI $\geq 25.0 \mathrm{~kg} / \mathrm{m}^{2}$; (2) fasting serum glucose concentration $\geq 6.1 \mathrm{mmol} / \mathrm{L}$ or 2 hours postprandial serum glucose concentration $\geq 7.8 \mathrm{mmol} / \mathrm{L}$; (3) blood pressure $\geq 140 / 90 \mathrm{~mm} \mathrm{Hg}$; or (4) dyslipidaemia: fasting serum triglyceride concentration $\geq 1.7 \mathrm{mmol} / \mathrm{L}$ or high-density lipoprotein (HDL)-cholesterol concentration $<0.9 \mathrm{mmol} / \mathrm{L}$ in men or $<1.0 \mathrm{mmol} / \mathrm{L}$ in women. Individuals who had been diagnosed with hypertension or diabetes and used antihypertensive or antidiabetic medications met the criteria for hypertension or hyperglycaemia. $^{14}$

\section{Statistical analysis}

All statistical analyses were performed with the SPSS V.24.0 program (SPSS). Normally, distributed and continuous variables were presented as means (SD), and categorical variables were presented as percentages. Student's t-test was used to test for significant differences in continuous data between two groups. The $\chi^{2}$ test was used to compare the differences in categorical variables. The multiple logistic regression model was use to analyse the risk factor of metabolic syndrome. A p-value less than 0.05 was considered statistically significant.

\section{Patient and public involvement}

Patients and public were not invited to comment on study design or conduction of the survey. However, they will be informed of the study results through publications.

\section{RESULTS}

Anthropometric and blood pressure characteristics of the participants are shown in table 1. In general, men had higher height, BMI, systolic and diastolic blood pressure, fasting serum glucose, triglyceride and lower HDL cholesterol when compared with women $(\mathrm{p}<0.001$ for all comparisons). Township residents were younger, taller, and had higher BMI, fasting serum glucose, triglyceride 
Table 1 Characteristics of the participants by gender and region

\begin{tabular}{|c|c|c|c|c|c|}
\hline & Total $(n=5053)$ & Men $(n=2221)$ & Women $(n=2832)$ & Township (n=769) & Countryside $(n=4284)$ \\
\hline Age (years) & $41.8(13.6)$ & $42.0(13.9)$ & $41.7(13.4)$ & $38.1(12.3) \dagger$ & $42.5(13.7)$ \\
\hline Height (cm) & $165.3(8.1)$ & $171.1(6.5)^{\star \star \star}$ & $160.8(6.1)$ & $166.1(8.2)^{\star *}$ & $165.2(8.0)$ \\
\hline $\mathrm{SBP}(\mathrm{mm} \mathrm{Hg})$ & $127.3(23.7)$ & $129.7(23.6)^{\star \star \star}$ & $125.4(23.6)$ & $121.9(19.9) \dagger$ & $128.3(24.2)$ \\
\hline $\mathrm{DBP}(\mathrm{mm} \mathrm{Hg})$ & 81.5 (14.2) & $83.2(14.4)^{\star \star \star}$ & 80.2 (13.9) & 80.7 (13.3) & $81.7(14.4)$ \\
\hline $\mathrm{TG}(\mathrm{mmol} / \mathrm{L})$ & $1.2(0.9)$ & $1.3(1.2)^{\star \star \star}$ & $1.1(0.5)$ & $1.5(1.7) \dagger$ & $1.1(0.6)$ \\
\hline HDL (mmol/L) & $1.29(0.12)$ & $1.27(0.11)^{\star \star \star}$ & $1.30(0.13)$ & $1.26(0.15) \dagger$ & $1.29(0.11)$ \\
\hline
\end{tabular}

Data are mean (SD).

${ }^{*} \mathrm{p}<0.05$ for township versus countryside. ${ }^{* \star} \mathrm{p}<0.01$ for township versus countryside. ${ }^{\star * \star} \mathrm{p}<0.001$ for men versus women. $\uparrow p<0.001$ for township versus countryside.

BMI, body mass index; DBP, diastolic blood pressure; FBG, fasting serum glucose; HDL, high-density lipoprotein; SBP, systolic blood pressure; TG, triglyceride.

and lower systolic blood pressure and HDL cholesterol than their counterparts in countryside areas $(\mathrm{p}<0.001$ for age, BMI, systolic blood pressure, triglyceride and HDL cholesterol, $\mathrm{p}<0.01$ for height, $\mathrm{p}<0.05$ for fasting serum glucose).

Table 2 shows the prevalence of metabolic syndrome and individual components of metabolic syndrome. The overall prevalence of metabolic syndrome in Derong was $3.6 \%(5.9 \%$ and $1.8 \%$ in men and women; $6.6 \%$ and $3.0 \%$ in township areas and countryside areas, respectively). Men had a higher prevalence of metabolic syndrome and all the four components than women in the total population and township and countryside subgroups ( $\mathrm{p}<0.001$ for all comparisons). The prevalence of metabolic syndrome, obesity (defined as BMI $\geq 25.0 \mathrm{~kg} / \mathrm{m}^{2}$ ), dyslipidaemia and hyperglycaemia or medication use was higher in township areas compared with countryside areas. While the prevalence of hypertension or medication use was higher in countryside areas than in township areas $(\mathrm{p}<0.001)$.
Overall, $35.3 \%, 19.4 \%$ and $5.9 \%$ of men and $32.7 \%$, $10.3 \%$ and $1.8 \%$ of women in Derong had one, two, three or more components (defined as metabolic syndrome) of metabolic syndrome, respectively (table 3 ). The prevalence of having one component of metabolic syndrome was similar in men and women and was higher in countryside than in township residents $(\mathrm{p}<0.05)$. Township residents had higher prevalence of having two or more components of metabolic syndrome than their countryside counterparts $(20.4 \%$ vs $13.2 \%, 4.8 \%$ vs $2.6 \%$ and $1.8 \%$ vs $0.4 \%$, respectively). Among township residents, more men had one or more components of metabolic syndrome than women $(\mathrm{p}<0.05)$. While in countryside, men were more likely to have two or three components of metabolic syndrome than women $(p<0.01)$.

The distribution of participants increased with age until age 50 years, and then decreased with age. Meanwhile, the prevalence of metabolic syndrome increased with age among men and women until age 60 years, when the prevalence decreased among men and slightly

Table 2 Prevalence of metabolic syndrome and individual components of metabolic syndrome by gender and region

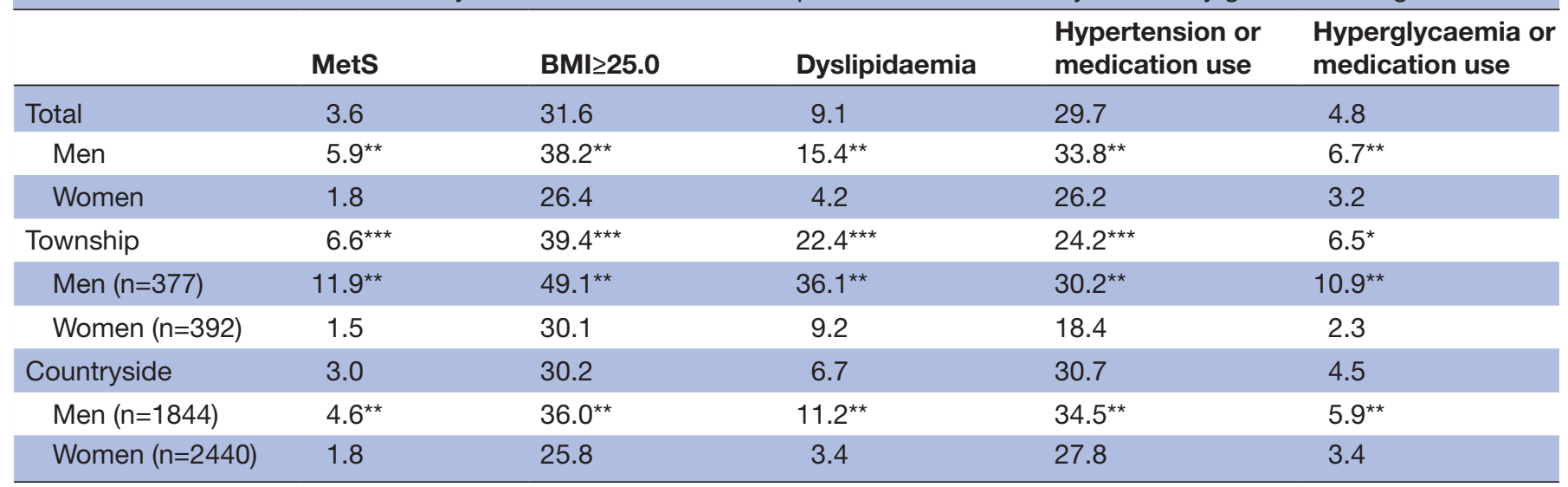

Data are percentage.

${ }^{*} \mathrm{p}<0.05$ for township versus countryside. ${ }^{* *} \mathrm{p}<0.001$ for men versus women. ${ }^{* *} \mathrm{p}<0.001$ for township versus countryside.

BMI, body mass index; MetS, metabolic syndrome. 
Table 3 Prevalence of one or more components of metabolic syndrome by gender and region

\begin{tabular}{lllll}
$\begin{array}{l}\text { Number of } \\
\text { metabolic } \\
\text { abnormalities }\end{array}$ & $\mathbf{1}$ & $\mathbf{2}$ & $\mathbf{3}$ & $\mathbf{4}$ \\
\hline Total & 33.9 & 14.3 & 3.0 & 0.6 \\
Men & 35.3 & $19.4^{\star \star}$ & $4.9^{\star \star}$ & $1.0^{\star \star}$ \\
Women & 32.7 & 10.3 & 1.5 & 0.3 \\
\hline Township & $28.0^{\star \star \star}$ & $20.4^{\star \star \star}$ & $4.8 \dagger$ & $1.8^{\star \star \star}$ \\
Men & $31.6^{\star}$ & $26.5^{\star \star}$ & $8.2^{\star \star}$ & $3.4^{\star \star}$ \\
Women & 24.5 & 14.5 & 1.5 & 0.3 \\
Countryside & 34.9 & 13.2 & 2.6 & 0.4 \\
Men & 36.1 & $18.0^{\star \star}$ & $4.2^{\star \star}$ & 0.5 \\
Women & 34.1 & 9.6 & 1.5 & 0.3 \\
\hline
\end{tabular}

Data are percentage. Metabolic abnormalities: body mass index $\geq 25.0 \mathrm{~kg} / \mathrm{m}^{2}$, dyslipidaemia, hypertension or medication use, and hyperglycaemia or medication use.

${ }^{*} p<0.05$ for men versus women. ${ }^{* *} p<0.01$ for men versus women. ${ }^{* *} p<0.001$ for township versus countryside. $\uparrow p<0.01$ for township versus countryside.

increased among women until age 70 years then slightly decreased. The prevalence of all the four components of metabolic syndrome increased with age $(p<0.05)$. In young people, more men had metabolic abnormality than women, and with the increase of age, the prevalence of metabolic abnormalities tended to be close between men and women (table 4). Therefore, in general, the prevalence of metabolic syndrome in men and women was $0.4 \%$ and $0.2 \%$ in those aged $18-29$ years, $4.3 \%$ and $0.4 \%$ in the $30-39$ year age group, $8.2 \%$ and $1.6 \%$ for age $40-49$ years, $10.8 \%$ and $4.7 \%$ in those aged $50-59$ years, $7.4 \%$ and $4.8 \%$ for age $60-69$ years, and $6.3 \%$ and $4.5 \%$ in the $\geq 70$ year age group. The prevalence of metabolic syndrome was significantly higher in men than in women for age $30-39$ years, $40-49$ years and $50-59$ years groups (figure 1).

Among the adults in Derong County, men, township, middle and old age residents had a higher risk of metabolic syndrome. The analysis of the risk factors of each component of metabolic syndrome showed that: (1) men had a higher risk of obesity, dyslipidaemia, hypertension and hyperglycaemia than women; (2) township residents had a higher risk of obesity, dyslipidaemia, hyperglycaemia and a lower risk of hypertension than countryside residents; (3) middle age residents had a higher risk of obesity, dyslipidaemia, hypertension and hyperglycaemia, while old age residents had a lower risk of obesity and a much higher risk of hypertension and hyperglycaemia; (4) compared with people living at moderate altitude

Table 4 Age-specific prevalence of individual components of metabolic syndrome

\begin{tabular}{|c|c|c|c|c|c|}
\hline Age (years) & Gender & $\mathrm{BMI} \geq 25.0$ & Dyslipidaemia & $\begin{array}{l}\text { Hypertension or } \\
\text { medication use }\end{array}$ & $\begin{array}{l}\text { or medication } \\
\text { use }\end{array}$ \\
\hline \multirow[t]{3}{*}{$18-29$} & Total $(n=1000)$ & 20.9 & 6.4 & 6.4 & 0.7 \\
\hline & Men $(n=455)$ & $28.4^{\star \star \star}$ & $9.7^{\star \star \star}$ & $10.1^{\star \star \star}$ & 0.7 \\
\hline & Women $(n=545)$ & 14.7 & 3.7 & 3.3 & 0.7 \\
\hline \multirow[t]{3}{*}{ 30-39 } & Total $(n=1302)$ & 31.3 & 9.0 & 15.4 & 2.6 \\
\hline & Men $(n=541)$ & $43.8^{* * \star}$ & $18.3^{\star \star \star}$ & $19.4^{\star \star}$ & $4.1^{\star \star}$ \\
\hline & Women $(n=761)$ & 22.5 & 2.4 & 12.6 & 1.6 \\
\hline \multirow[t]{3}{*}{$40-49$} & Total $(n=1449)$ & 40.8 & 10.6 & 30.0 & 5.7 \\
\hline & Men $(n=638)$ & $47.6^{\star \star \star}$ & $18.5^{\star \star \star}$ & $34.5^{\star \star}$ & $8.5^{\star \star \star}$ \\
\hline & Women $(n=811)$ & 35.4 & 4.3 & 26.5 & 3.6 \\
\hline \multirow[t]{3}{*}{$50-59$} & Total $(n=684)$ & 34.6 & 11.1 & 53.9 & 7.9 \\
\hline & Men $(n=305)$ & 34.8 & $17.0^{*}$ & 57.4 & $10.5^{*}$ \\
\hline & Women $(n=379)$ & 34.6 & 6.3 & 51.2 & 5.8 \\
\hline \multirow[t]{3}{*}{$60-69$} & Total $(n=450)$ & 24.7 & 8.9 & 68.0 & 11.3 \\
\hline & Men (n=202) & 26.2 & $11.9^{*}$ & 71.8 & $16.8^{\star \star}$ \\
\hline & Women $(n=248)$ & 23.4 & 6.5 & 64.9 & 6.9 \\
\hline \multirow[t]{3}{*}{$\geq 70$} & Total $(n=168)$ & 24.4 & 6.5 & 75.6 & 7.1 \\
\hline & Men $(n=80)$ & 25.0 & 7.5 & 75.0 & 5.0 \\
\hline & Women $(n=88)$ & 23.9 & 5.7 & 76.1 & 9.1 \\
\hline
\end{tabular}

Data are percentage.

${ }^{*} \mathrm{p}<0.05$ for men versus women. ${ }^{* *} \mathrm{p}<0.01$ for men versus women. ${ }^{* *} \mathrm{p}<0.001$ for men versus women. BMI, body mass index. 


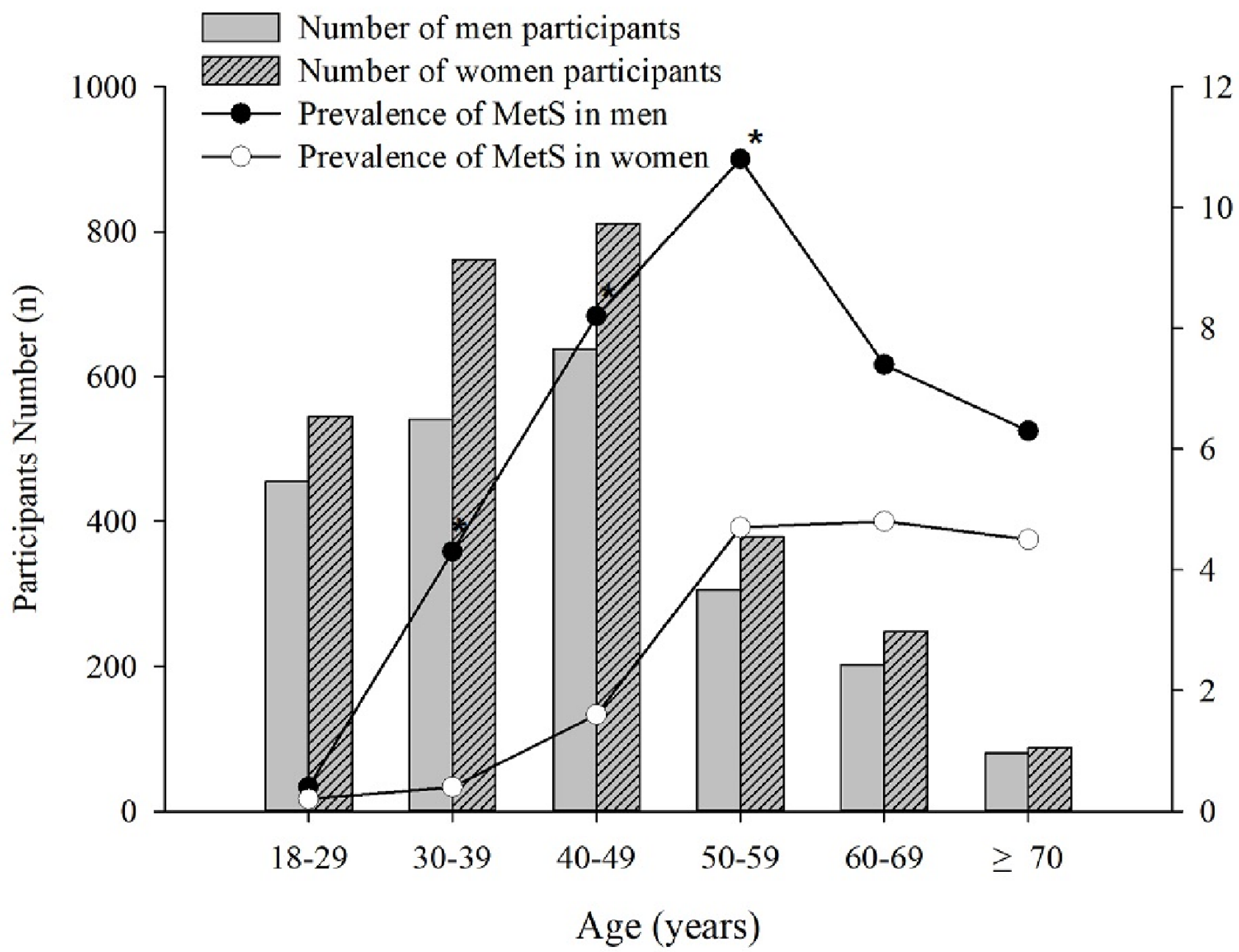

Figure 1 Age distributions of participants and age-specific prevalence of metabolic syndrome by gender. MetS, metabolic syndrome. ${ }^{*} \mathrm{p}<0.05$ for men versus women.

(2000-2499 m), those living at high altitude (2500-2999 $\mathrm{m})$ and very high altitude $(\geq 3000 \mathrm{~m})$ had a lower risk of dyslipidaemia and a higher risk of hypertension; in addition, living in very high altitude decreases the risk of having obesity (table 5).

\section{DISCUSSION}

In this study, the results estimate that 580 (or 3.6\%) adult native residents of Derong have metabolic syndrome as defined by the CDS criteria. Although the prevalence of metabolic syndrome in Derong was much lower than previous researches in Chinese population, the prevalence of obesity and one or two components of metabolic syndrome was similar with these studies. ${ }^{41}$ As Derong County was an economy less developed region of western China, the relatively high prevalence of obesity and metabolic abnormalities indicates that obesity and metabolic syndrome have become serious public health challenges in China.

The Health Examination Program of Derong County was a welfare program held by the government, which was designed to detect common chronic disease for every native resident in Derong. To achieve this goal, the examination teams visited all the villages throughout the county. Taking migrant workers into account, the high participate and response rate made the present study well represent the overall age, gender and regional distributions of the whole county.

Few large-scale surveys have been done in high-altitude residents of China. A survey of 692 participants at $3700 \mathrm{~m}$ in Tibet reported that the prevalence of metabolic syndrome was $8.2 \% .^{15}$ Another study of 1659 Tibetan adults revealed that the prevalence of clustering of $\geq 3$ cardiovascular disease risk factors (can be considered as metabolic syndrome) was $20.9 \% .{ }^{16}$ Compared with these studies, people living in Derong have lower prevalence of metabolic syndrome than those high-altitude areas. The reasons maybe: (1) in the former study, participants' age was from 30 to 80 years, since the younger population has much lower prevalence of metabolic syndrome, it may overestimate the prevalence of metabolic syndrome; (2) in the latter study, besides the components of metabolic syndrome, it took smoking into account, thus may increase the prevalence of metabolic syndrome. 
Table 5 Multiple logistic regression analysis of risk factors of metabolic syndrome and its components

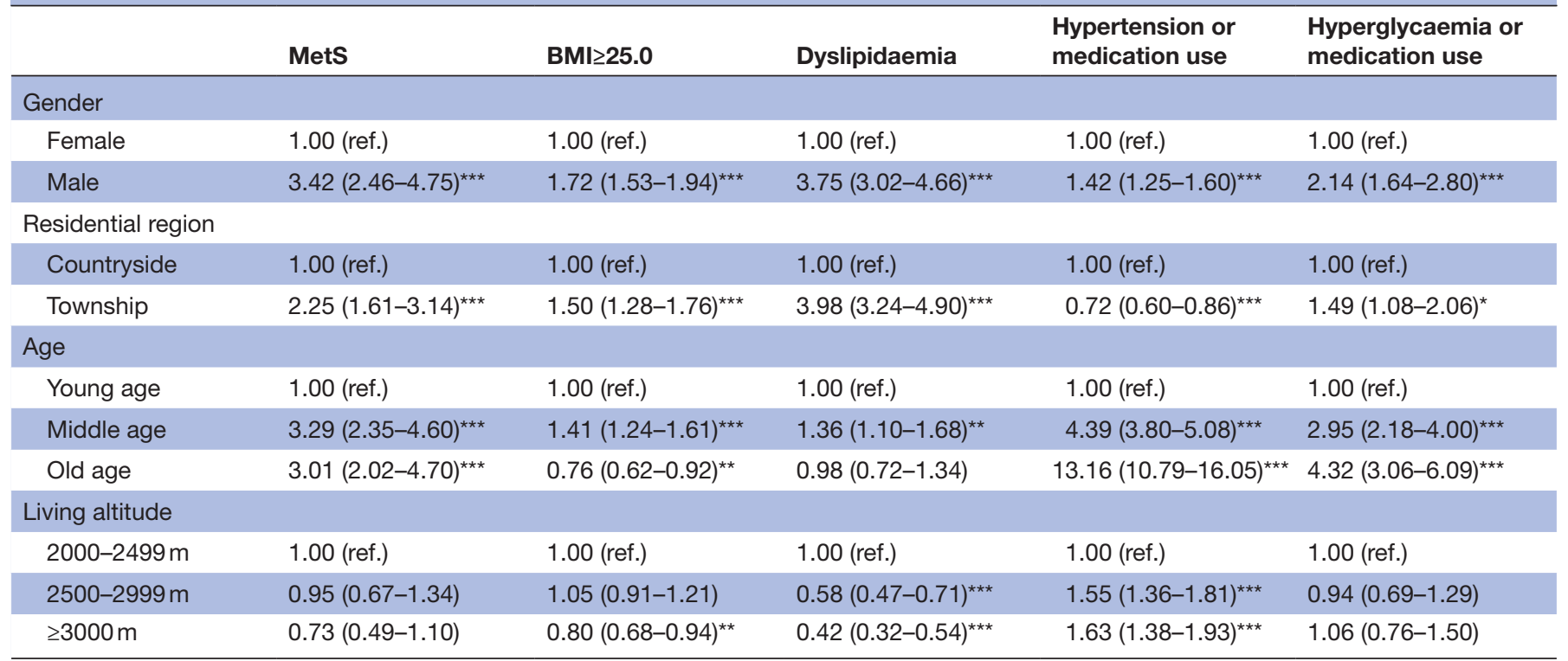

Data are OR (95\% Cls). Young age: 18-44 years. Middle age: 45-59 years. Old age: $\geq 60$ years. Multiple ogistic regressions were used to assess the association between gender, residential region, age and living altitude and metabolic syndrome (MetS) and its components. ${ }^{*} \mathrm{p}<0.05,{ }^{* *} \mathrm{p}<0.01,{ }^{* * *} \mathrm{p}<0.001$.

BMI, body mass index.

The present study shows that the main metabolic abnormalities were obesity and hypertension, while the prevalence of dyslipidaemia and hyperglycaemia was relatively low at high altitude. Our finding that the prevalence of obesity did not match the prevalence of hyperglycaemia at high altitude was also reported in a small-scale survey of Tibetan immigrants in India. The author discusses the reasons maybe that the cellular response to chronic hypoxia at high altitude may enhance cellular glucose uptake, glycolysis and glycogenesis, but decrease hepatic gluconeogenesis. As a result, it leads to decrease in blood glucose, haemoglobin A1c and increase insulin sensitivity. Moreover, the cold weather and chronic hypoxia at high altitude cause calorie intake increase and energy expenditure decrease, which eventually leads to positive energy gain, and induces overweight and obesity. ${ }^{17}$ Our study revealed that although living altitude affected the risk of different components of metabolic syndrome, there was no dose-response effect between altitude and the risk of metabolic syndrome. This result may due to the opposite effect of altitude on hypertension, obesity and dyslipidaemia. In addition, the low prevalence of metabolic syndrome in Derong may also be one of the reasons.

Our findings showed a higher prevalence of each individual components of metabolic syndrome as well as a much higher prevalence of metabolic syndrome in men compared with women, especially in township and young people. This result was different from other study of Chinese population, in which the prevalence of metabolic syndrome was higher in women than that in men. ${ }^{11} 12 \mathrm{In}$ addition, it is reported that the prevalence of obesity is greater in women than in men worldwide, especially in developing countries. ${ }^{1819}$ The reason for our results might be more dietary energy intake and alcohol consumption in men than women, in township than countryside and in youth than elderly based on the Tibetan lifestyle of Derong. Another finding of our study was that there was a much more rapid increase in the prevalence of metabolic syndrome with age in men before 60 years old and more rapid decrease thereafter. The lower prevalence of metabolic syndrome in women younger than 50 years old and great increase thereafter might be due the protective effect of oestrogen on cardiovascular risk factors. ${ }^{20}$ The rapid decrease in prevalence of metabolic syndrome in men after age 60 years might be due to a survivor effect, that is, people who had metabolic syndrome were more likely to die before that age and were not recruited in our study. The combination of these two factors makes the gap between men and women in metabolic syndrome prevalence gradually narrow with the increase of age in over 50 years old.

Metabolic syndrome is usually more prevalent in urban area than in rural area. Economic difference and change in dietary pattern might help explain the difference between the two regions. Our results were also consistent with those findings. ${ }^{112}$ The difference between urbanised lifestyle in township areas and husbandry lifestyle in countryside areas might contribute to the differences in the prevalence of metabolic syndrome. Different from other components of metabolic syndrome, the hypertension rate in countryside was greater than in township. Previous studies in China have documented this regional variation in the prevalence of hypertension. ${ }^{11} 21$ The lower levels of known, treatment and control rate of hypertension in countryside area might be the reason for this phenomenon. A recent global research finds that in low-income 
and middle-income regions, BMI is increasing faster in rural areas than in cities in the past three decades. In these regions, agriculture is increasingly mechanised, cars are more used as income increases and road infrastructure improves, and tap water connection to every family makes some household tasks no longer needed. ${ }^{22}$ Although there is still more metabolic syndrome in township areas than in countryside areas in Derong, the similar changes as mentioned above in Derong suggest that it is likely to have more rapid increase in metabolic syndrome in countryside.

Despite several diagnostic criteria of metabolic syndrome such as WHO criteria, ${ }^{23}$ the National Cholesterol Education Program Expert Panel on Detection, Evaluation, and Treatment of High Blood Cholesterol in Adults (Adult Treatment Panel III (ATP III)) criteria, ${ }^{24}$ the International Diabetes Federation (IDF) criteria $^{25}$ and the CDS criteria, a worldwide accepted definition does not exist. Each definition is similar in focus on obesity, hyperglycaemia, hypertension and dyslipidaemia, but differs in how each of the individual components is defined. The WHO criteria define hyperglycaemia as the presence of diabetes, impaired glucose tolerance, impaired fasting glucose or insulin resistance and takes microalbuminuria into account. The ATP III criteria and the IDF criteria define obesity by waist circumference rather than BMI of the CDS criteria. The CDS criteria were used in the present study for the convenience in large-scale examination and its applicability for Chinese population.

Our study has several limitations. First, evidence show that compared with the ATP III criteria and the IDF criteria, the CDS criteria may underestimate the prevalence of metabolic syndrome ${ }^{12}$; moreover, the revised ATP III criteria have a specific cut-off of waist circumference for East Asians. Recently, an updated CDS criteria also use waist circumference to define obesity. ${ }^{26}$ Since the Health Examination Program of Derong County was not designed only for metabolic syndrome, we did not set waist circumference as the routine examination. In this situation, we use the CDS criteria to diagnose metabolic syndrome instead. We need explore the difference among these diagnostic criteria in the future research. Second, this is a cross-sectional study that does not allow us to draw any causal conclusions. Further longitudinal study is necessary to find out the causality between metabolic risk factors and metabolic syndrome at high altitude. Third, we determined the altitude of residents' living as the average altitude of their settlement from Google Maps, and it may have some errors with the actual altitude of residents' living. Fourth, in order to confirm the effect of altitude on metabolic factors, investigation and research in the similar altitude areas with different climatic conditions and lifestyles should be carried out. Fifth, to determine the impact of high altitude on metabolic abnormalities, we need further control cohort from different altitudes.

In conclusion, metabolic syndrome is not common among adults at high altitude in Derong. However, the prevalence of obesity and hypertension is relatively common, even similar to other places of China. In addition, men, township, middle and old age residents are more likely to have metabolic syndrome than women, countryside and young age residents. It is necessary to develop comprehensive national strategies for the prevention and treatment of the metabolic syndrome, obesity and hypertension especially for that high-risk population at high altitude in China. More different and updated criteria of metabolic syndrome are needed to confirm our findings in the study. Further longitudinal and multiregional studies are also needed to determine the effect of high altitude on metabolic syndrome.

\section{Author affiliations}

'Department of Endocrinology and Metabolism, Chengdu Third People's Hospital, Chengdu, Sichuan, China

${ }^{2}$ Huaxi MR Research Center, Department of Radiology, Sichuan University West China Hospital, Chengdu, China

${ }^{3}$ Department of Neurology, Chengdu Third People's Hospital, Chengdu, Sichuan, China

${ }^{4}$ Office of Administration, Pujiang County Center for Disease Control, Chengdu, Sichuan, China

${ }^{5}$ Department of Otorhinolaryngology, Chengdu Third People's Hospital, Chengdu, Sichuan, China

${ }^{6}$ Department of Cardiology, Chengdu Third People's Hospital, Chengdu, Sichuan, China

${ }^{7}$ Department of Medicine, Derong County People's Hospital, Derong, Sichuan, China ${ }^{8}$ Department of Hematology, Chengdu Third People's Hospital, Chengdu, Sichuan, China

${ }^{9}$ Department of Psychiatry, Sichuan University West China Hospital, Chengdu, China

AcknowledgmentThe authors thank the government of Derong County and the Health and Family Planning Commission of Derong County for the management assistance. They also thank the Derong county people's hospital for the data collection and technical assistance.

Contributors $\mathrm{XH}$ : designed the study, analysed the data and wrote the manuscript. $\mathrm{YH}$ : designed the study, collected and analysed the data. LD, XL, and WW: recruited subjects and collected data. LF: recruited subjects, collected data and performed the clinical examination. LL and XZ: analysed the data and did statistical analysis. QG: analysed the data and wrote the manuscript. LG: conceived and designed the experiments. WK: conceived and designed the experiments, responsible for the study.

Funding This work was supported by the National Natural Science Foundation of China (No. 81621003) and Science and Technology Projects of Sichuan Province (2015SZ0235).

Competing interests None declared.

Patient consent for publication Not required.

Ethics approval All procedures involving human subjects were approved by the ethics committee of the third people's hospital of Chengdu (20130179).

Provenance and peer review Not commissioned; externally peer reviewed. Data availability statement No data are available.

Open access This is an open access article distributed in accordance with the Creative Commons Attribution Non Commercial (CC BY-NC 4.0) license, which permits others to distribute, remix, adapt, build upon this work noncommercially, and license their derivative works on different terms, provided the original work is properly cited, appropriate credit is given, any changes made indicated, and the use is non-commercial. See: http://creativecommons.org/ licenses/by-nc/4.0/.

ORCID iD

Weihong Kuang http://orcid.org/0000-0001-7279-0556 


\section{REFERENCES}

1 GBD 2016 Causes of Death Collaborators. Global, regional, and national age-sex specific mortality for 264 causes of death, 19802016: a systematic analysis for the global burden of disease study 2016. Lancet 2017;390:1151-210.

2 Trevisan M, Liu J, Bahsas FB, et al. Syndrome X and mortality: a population-based study. risk factor and life expectancy Research Group. Am J Epidemiol 1998;148:958-66.

3 Song Q-B, Zhao Y, Liu Y-Q, et al. Sex difference in the prevalence of metabolic syndrome and cardiovascular-related risk factors in urban adults from 33 communities of China: the CHPSNE study. Diab Vasc Dis Res 2015;12:189-98.

4 Yu S, Guo X, Yang H, et al. An update on the prevalence of metabolic syndrome and its associated factors in rural northeast China. BMC Public Health 2014;14:877.

5 Zeng $\mathrm{H}$, Lin $\mathrm{H}$, Liu W, et al. Prevalence of metabolic syndrome among adults with liver function injury in rural area of Southwest China: a cross-sectional study. Sci Rep 2017;7:5518.

6 Mazidi M, Toth PP. Banach M. C-reactive protein is associated with prevalence of the metabolic syndrome, hypertension, and diabetes mellitus in US adults. Angiology 2017;3319717729288.

7 Woolcott OO, Castillo OA, Gutierrez C, et al. Inverse association between diabetes and altitude: a cross-sectional study in the adult population of the United States. Obesity 2014;22:2080-90.

8 Woolcott OO, Ader M, Bergman RN. Glucose homeostasis during short-term and prolonged exposure to high altitudes. Endocr Rev 2015;36:149-73.

9 Mingji C, Onakpoya IJ, Perera R, et al. Relationship between altitude and the prevalence of hypertension in Tibet: a systematic review. Heart 2015;101:1054-60.

10 Hirschler V. Cardiometabolic risk factors in native populations living at high altitudes. Int J Clin Pract 2016;70:113-8.

11 Gu D, Reynolds K, Wu X, et al. Prevalence of the metabolic syndrome and overweight among adults in China. The Lancet 2005;365:1398-405.

$12 \mathrm{Xi} \mathrm{B}, \mathrm{He} \mathrm{D}, \mathrm{Hu}$ Y, et al. Prevalence of metabolic syndrome and its influencing factors among the Chinese adults: the China health and nutrition survey in 2009. Prev Med 2013;57:867-71.

13 Perloff D, Grim C, Flack J, et al. Human blood pressure determination by sphygmomanometry. Circulation 1993;88:2460-70.
14 Metabolic Syndrome Research Group of Chinese Diabetes Society. Recommendations on metabolic syndrome of Chinese diabetes Society. Chin J Diabetes 2004;12:156-61.

15 Sherpa LY, Deji, Stigum H, et al. Prevalence of metabolic syndrome and common metabolic components in high altitude farmers and herdsmen at $3700 \mathrm{M}$ in Tibet. High Alt Med Biol 2013;14:37-44.

$16 \mathrm{Xu} \mathrm{S}$, Jiayong Z, Li B, et al. Prevalence and clustering of cardiovascular disease risk factors among Tibetan adults in China: a population-based study. PLoS One 2015;10:e0129966.

17 Lin BY, Genden K, Shen W, et al. The prevalence of obesity and metabolic syndrome in Tibetan immigrants living in high altitude areas in Ladakh, India. Obes Res Clin Pract 2017.

18 Garawi F, Devries K, Thorogood N, et al. Global differences between women and men in the prevalence of obesity: is there an association with gender inequality? Eur J Clin Nutr 2014;68:1101-6.

19 Kanter R, Caballero B. Global gender disparities in obesity: a review. Adv Nutr 2012;3:491-8.

20 Kim HM, Park J, Ryu SY, et al. The effect of menopause on the metabolic syndrome among Korean women: the Korean National health and nutrition examination survey, 2001. Diabetes Care 2007;30:701-6.

21 Wang J, Sun W, Wells GA, et al. Differences in prevalence of hypertension and associated risk factors in urban and rural residents of the northeastern region of the People's Republic of China: A cross-sectional study. PLoS One 2018;13:e0195340.

22 NCD Risk Factor Collaboration (NCD-RisC). Rising rural body-mass index is the main driver of the global obesity epidemic in adults. Nature 2019;569:260-4.

23 Alberti KG, Zimmet PZ, Definition ZPZ. Definition, diagnosis and classification of diabetes mellitus and its complications. Part 1: diagnosis and classification of diabetes mellitus provisional report of a who consultation. Diabet Med 1998;15:539-53.

24 Expert Panel on Detection, Evaluation, and Treatment of High Blood Cholesterol in Adults. Executive summary of the third report of the National cholesterol education program (NCEP) expert panel on detection, evaluation, and treatment of high blood cholesterol in adults (adult treatment panel III). JAMA 2001;285:2486-97.

25 Alberti KGMM, Zimmet P, Shaw J. Metabolic syndrome-a new world-wide definition. A consensus statement from the International diabetes Federation. Diabet Med 2006;23:469-80.

26 Jia W, Weng J, Zhu D, et al. Standards of medical care for type 2 diabetes in China 2019. Diabetes Metab Res Rev 2019;35:e3158. 